\section{SP4-40 A SYSTEMATIC REVIEW OF CLIMATE CHANGE' IMPACT AND INFECTIOUS DISEASE}

doi:10.1136/jech.2011.142976p.34

\section{SP4-42 ANTHROPOMETRIC MEASURES, FOOD HABITS AND PERCEIVED STRESS AMONG URBAN SOUTH INDIANS}

doi:10.1136/jech.2011.142976p.36
F F Jahani, ${ }^{*}$ E Ahmadnezhad. Tehran University of Medical Sciences, Tehran, Iran

Backgroumd Biological and ecological processes of climate changes could be influence infectious disease transmission. The aim of this systematic review was evaluated the influence of climatic factors on infectious disease.

Methods Systematic searches were conducted via a range of related databases such as Pubmed, Medline, EBSCO and ISI Web of Knowledge. Searches focused upon papers published in English between 1995 and 2010. Retrieved papers were studied by the authors in order to inform the topic and theme. The following terms were used for searching: Climate Change, infectious disease, communicable disease, malaria, eltor, Lishmania, time series and indirect pathway.

Results A total of 290 publications were retrieved, of which 150 met the inclusion criteria. There were classified and are discussed according to their focus on disease classification relevant to climate/ health relationships.

Conclusion Many studies showed seasonal fluctuations in infectious disease but few of them have documented long-term trends in climatic associations. There were a causal relationship between climate change and vector born and water born diseases. For preventive policies the epidemiological data can be shared with policy makers.

\section{SP4-41 DETERMINANTS OF HUMAN BRUCELLOSIS IN A REGION OF IRAN: A CASE-CONTROL STUDY}

doi:10.1136/jech.2011.142976p.35

${ }^{1} \mathrm{~A}$ Bahonar, ${ }^{*}{ }^{2} \mathrm{M}$ Dakhili, ${ }^{3} \mathrm{M}$ S Motlagh, ${ }^{3} \mathrm{~A}$ Anvarizadeh. ${ }^{1}$ Tehran University, Tehran, Iran; ${ }^{2}$ Oom Branch, Islamic Azad University, Oom, Iran; ${ }^{3}$ Iranian Veterinary Organization, Tehran, Iran

Introduction Although contact with animals and their infected products are known as a main risk factors of brucellosis, but climate conditions, type and management aspects of animal husbandry and people nutritional behaviours on dairy products consumption in each region, are the factors affecting incidence pattern of the disease in each country. Human brucellosis is a notifiable disease in many countries, but official figures do not fully reflect the number of people infected each year and true incidence has been estimated to be between 10 and 25 times higher than what reported figures indicate. Therefore burden of this disease in Iran with about 25000 new cases in 2005 is very important from the view point of public health.

Methods In this study in order to determine the risk factors of brucellosis and infected animals, a multicenter case-control study was conducted in Qom in 2006. A total of 170 cases with serological diagnosis and physician confirm of brucellosis answered to questions. Control group was selected from patients without brucellosis. In all 170 parsons were selected as controls.

Results OR for all independent variables was computed and revealed that: occupational contact with animals, $\{\mathrm{OR}=5.4$ (3.4-8.9) $\}$, consumption of at least one unpasteurised dairy products, $\{O R=2.96(1.33-6.58)\}$ were associated with the disease. Butter consumption was a risk factor, $\{\mathrm{OR}=6.5(3.3-12.7)\}$. Also rural residency was another determinant of disease $(p<0.01)$

Conclusion Public health education for people with livestock exposure and monitoring for consumption of pasteurised dairy products can be the main intervention in human population for control of brucellosis.
${ }^{1} \mathrm{H}$ J Parr, ${ }^{2} \mathrm{~V}$ Mohan, ${ }^{3} \mathrm{~S}$ Bharma, ${ }^{1} \mathrm{~B} \mathrm{~J}$ Stewart-Knox. ${ }^{*}$ NICHE, University of Ulster, Coleraine, UK; ${ }^{2}$ Madras Diabetes Research Foundation \& Dr. Mohan's Diabetes Specialities Centre, Chennai, Tamil Nadu, India; ${ }^{3}$ Apollo Hospitals Group, Chennai, Tamil Nadu, India

Associations between waist circumference, Body Mass Index (BMI), food habits and perceived stress were investigated in urban dwelling South Indian adults $(\mathrm{N}=347)$. The questionnaire was informed by prior qualitative research, piloted and administered by interviewassisted survey in English and Tamil. A 25-item Food Frequency Questionnaire (FFO) assessed eating habits on a seven point scale from "never" to "five times daily". Perceived stress (PS) was assessed using PSS4 "global measure of perceived stress" scale (Cohen et al, 1983) for which responses were recorded on a five point Likert scale ("never" to "very often"). BMI, body weight and waist circumference (WC) were recorded. Data were analysed by Pearson correlations using SPSS v17.0. BMI was associated with being female, while measures of waist and weight were associated with being male Positive correlations were found between age and waist circumference, but not BMI. (PS) "unable to control things" was associated with being female. A weak association between PS "difficulties piling so high, you cannot overcome them" and weight was found. There were no other associations between PS and other anthropometric measures. Lower PS was associated with more frequent consumption of coffee, buttermilk, skimmed milk, paneer, curd, prawns, potatoes, sweets/biscuits, butter, fruit, vegetables and alcoholic drinks. Higher perceived stress was associated with more frequent consumption of fish, daal, chocolate and coconut milk. Further analyses are required to determine the degree to which stress is an antecedent or consequence of dietary habits.

Funding This analysis has been supported by the HRB (Ireland) Centre for Health Research.

\section{NEGLECTED CONDITIONS}

\section{SP5-1 ORGANISATIONAL ROLE STRESS INDICES AFFECTING BURNOUT AMONG NURSES}

doi:10.1136/jech.2011.142976p.37

$\mathrm{J} \mathrm{L}$ Lu. ${ }^{*}$ National Institutes of Health, University of the Philippines Manila, Manila, The Philippines

This is a cross sectional study, which aimed to determine the interaction between situational, factors, role stressors, hazard exposure and personal factors among 246 nurses consisting most of females $(78.5 \%)$ from the different wards and units in the Philippine General Hospital (PGH). Almost half (49.6\%) of the respondents reported being ill due to work in the past year, and $56.1 \%$ missed work because of an illness. Correlation statistics using the Spearman's $\rho$ showed organisational role stressors was most significant in burnout among nurses in the Philippine's largest tertiary hospital. Organisational role stressors consisted of ten dimensions, namely: (1) Inter-role Distance (IRD); (2) Role Stagnation (RS); (3) Role Expectation Conflict (REC); (4) Role Erosion (RE); (5) Role Overload (RO); (6) Role Isolation (RI); (7) Personal Inadequacy (PI); (8) Selfrole Distance (SRD); (9) Role Ambiguity; and (10) Resource Inadequacy (RIn). The contribution of the study is in advancing new concepts in the already existing framework of burnout, and thus, can assist nurses and hospital administration on how to control this problem. 